\title{
PROFIL CAPAIAN IMUNISASI DASAR/ LANJUTAN PADA BADUTA SEBELUM DAN SELAMA PANDEMI COVID-19
}

\author{
Wiyarni Pambudi ${ }^{1}$, Sari M.D Nataprawira ${ }^{2}$, Zita Atzmardina ${ }^{3}$, Sylvia Regina ${ }^{4}$ \\ ${ }^{1}$ Bagian Ilmu Kesehatan Anak, Fakultas Kedokteran, Universitas Tarumanagara Jakarta \\ Email:wiyarni@fk.untar.ac.id \\ ${ }^{2}$ Bagian Histologi Imunologi, Fakultas Kedokteran, Universitas Tarumanagara Jakarta \\ Email: sarid@fk.untar.ac.id \\ ${ }^{3}$ Bagian Ilmu Kesehatan Masyarakat, Fakultas Kedokteran, Universitas Tarumanagara Jakarta \\ Email: zitaa@fk.untar.ac.id \\ ${ }^{4}$ Program Studi Sarjana Kedokteran, Fakultas Kedokteran, Universitas Tarumanagara Jakarta \\ Email: sylvia.405180212@stu.untar.ac.id
}

Masuk : 10-03-2021, revisi: 28-04-2021, diterima untuk diterbitkan : 20-05-2021

\begin{abstract}
ABSTRAK
Perubahan global dari pandemi penyakit coronavirus 2019 (COVID-19) dapat mengganggu layanan penyelamatan hidup yang kritis seperti imunisasi rutin, sehingga meningkatkan kerentanan populasi terhadap wabah Penyakit yang Dapat Dicegah Dengan Imunisasi (PD3I). Ketika kasus COVID-19 meningkat dan pemerintah menerapkan pembatasan sosial, kunjungan pasien rawat jalan menurun secara signifikan. Hal ini mengakibatkan penurunan angka imunisasi anak. Penelitian ini bertujuan untuk mengetahui profil capaian imunisasi dasar dan imunisasi lanjutan sebelum dan selama pandemi COVID-19, profil capaian imunisasi rutin di 34 provinsi serta hubungannya dengan status zona risiko pandemi. Data yang dianalisis pada studi observasional deskriptif dengan desain potong lintang ini adalah laporan rutin pelayanan imunisasi Sub Direktorat Imunisasi, Kementerian Kesehatan RI. Kajian terhadap capaian imunisasi 34 provinsi menunjukkan terjadi penurunan praktik pelayanan imunisasi dasar sebesar $17,0 \%(\mathrm{p}<0,0005)$ dan imunisasi lanjutan $-12,9 \%(\mathrm{p}<0,0005)$ dibandingkan sebelum masa pandemi. Uji statistik menyatakan profil capaian imunisasi dasar memiliki hubungan yang bermakna secara statistik $(\mathrm{p}<0,05)$ terhadap peningkatan kasus di suatu wilayah, namun berkorelasi lemah berlawanan $(-0,5<\mathrm{r}<-0,3)$. Penurunan cakupan imunisasi lanjutan yang terjadi selama pandemi COVID-19 berkorelasi sangat lemah berlawanan $(r>-0,3)$ dan tidak memiliki hubungan yang bermakna secara statistik $(\mathrm{p}>0,05)$ dengan zona risiko pandemi. Dalam situasi pandemi, petugas kesehatan dihadapkan pada tantangan tambahan untuk mempertahankan dan memperkuat imunisasi rutin seperti kondsi sebelum pandemi. Peningkatan upaya komunikasi mengenai pentingnya vaksinasi akan bermanfaat, karena efek pandemi COVID-19 telah menyoroti ancaman penyakit menular dan meningkatkan kesadaran akan praktik imunisasi rutin.
\end{abstract}

Kata Kunci: Imunisasi Dasar/Lanjutan, Pandemi COVID-19.

\begin{abstract}
The global progression of the coronavirus disease 2019 (COVID-19) pandemic may disrupt critical life-saving services such as routine immunization, thus increasing the susceptibility of population to outbreaks of vaccinepreventable diseases (VPDs). As COVID-19 cases increased and government implemented stay-at-home orders, outpatient visits declined significantly. This condition may decrease the rates of childhood immunization. This study aims to determine the profile of basic immunization and follow-up immunization achievements before and during the COVID-19 pandemic, the profile of routine immunization outcomes in 34 provinces and their relationship to the pandemic risk zone status. The data analyzed in this descriptive observational study with a cross-sectional design were routine reports on immunization services at Sub Directorate of Immunization, MoH. Profile on immunization coverages showed a decrease in basic immunization service practices by $-17.0 \%$ ( $p<0.0005)$ and advanced immunization $-12.9 \%$ ( $p<0.0005$ ) compared to before the pandemic period. Statistical test showed that the basic immunization achievement profile had a statistically significant relationship $(p<0.05)$ with the increase in cases in a region, but had a weak correlation $(-0.5<r<-0.3)$. The decrease in advanced immunization had a very weak correlation ( $r>-0.3)$ and had no statistically significant relationship $(p>0.05)$ with an increase in COVID-19 cases. During pandemic situation, health providers are presented with the additional challenge of maintaining and strengthening routine vaccination as previously done before pandemic. Increasing communication efforts regarding the importance of vaccination will be worthwhile, as the effect of the COVID-19 pandemic has highlighted the threat of an infectious disease and has increased awareness of the routine immuization practices.
\end{abstract}

Keywords: Routine Immunization, Pandemic COVID-19. 


\section{PENDAHULUAN \\ Latar Belakang}

Pandemi COVID-19, yang secara resmi diumumkan oleh World Health Organization (WHO) pada 11 Maret 2020, tidak dapat dipungkiri terus menyebar luas dan telah memengaruhi berbagai aspek kehidupan. Data yang diperbarui berkala dari website https://covid19.who.int pada tanggal 10 April 2021 menyatakan jumlah kasus terkonfirmasi mencapai 136.035.520 kasus COVID-19 dengan 2.939.546 kematian di seluruh dunia. Individu yang terinfeksi merasakan efek gangguan neurologis, pernapasan, gastrointestinal, dan sebagainya. Sedangkan mereka yang belum terinfeksi mengalami stres karena takut tertular, cemas menghadapi pandemi yang tidak terprediksi kapan dan bagaimana akan berakhir, serta gangguan kehidupan sehari-hari akibat penerapan protokol Pembatasan Sosial Berskala Besar (PSBB). Pada sistem pelayanan kesehatan, terjadi penurunan kunjungan ke poliklinik karena kekhawatiran terinfeksi dan berkurangnya aksesibilitas ke fasilitas kesehatan menyesuaikan protokol pembatasan sosial. (Roberton, et al, 2020). Salah satu pelayanan yang perlu lebih diperhatikan adalah dampak COVID-19 terhadap pelayanan kesehatan anak esensial, seperti pemantauan pertumbuhan/perkembangan dan pemberian imunisasi rutin.

Kendala pelaksanaan imunisasi dasar dan lanjutan untuk anak usia di bawah dua tahun (baduta) dapat menimbulkan peningkatan risiko Penyakit yang Dapat Dicegah Dengan Imunisasi (PD3I) dalam waktu dekat, dan jangka panjang. Kondisi ini akan meningkatkan beban pada sistem kesehatan dan jaminan sosial yang sudah sangat terancam. Kegagalan imunisasi berisiko menghadirkan Kejadian Luar Biasa (KLB) dan wabah penyakit yang dapat dicegah dengan imunisasi (PD3I) (Nelson, 2020) (UNICEF, 2020). Secara spesifik, menurut prediksi World Health Organization (WHO), United Nations International Children's Emergency Fund (UNICEF), dan Global Alliance for Vaccines and Immunization (GAVI) kesehatan ibu dan anak di negara-negara berpenghasilan rendah paling terpengaruh dengan peningkatan morbiditas dan mortalitas akibat runtuhnya sistem pelayanan kesehatan rutin yang secara tidak langsung terganggu oleh pandemi COVID-19. (WHO, UNICEF, 2020)

Sebelum pandemi, cakupan imunisasi rutin pada baduta di sebagian besar wilayah Indonesia menunjukkan tren yang semakin baik dari tahun ke tahun, kecuali di provinsi Aceh, Papua, dan beberapa daerah di luar pulau Jawa. Bertambah peliknya situasi layanan kesehatan rutin saat pembatasan sosial, mendorong penulis untuk mengetahui cakupan pelayanan imunisasi anak pada masa pandemi. Hasil penelitian ini diharapkan dapat menjadi masukan untuk perbaikan pelayanan kesehatan terutama dalam meningkatkan cakupan imunisasi anak.

\section{Rumusan Masalah}

Penelitian ini bertujuan untuk mengetahui profil capaian imunisasi dasar dan imunisasi lanjutan sebelum dan selama pandemi COVID-19, profil capaian imunisasi rutin di 34 provinsi dan hubungannya dengan status zona risiko pandemi.

\section{METODE PENELITIAN}

Penelitian ini menggunakan rancangan observasional deskriptif dengan desain potong lintang. Kriteria capaian imunisasi dasar/lanjutan lengkap mengikuti Peraturan Menteri Kesehatan Republik Indonesia Nomor 12 Tahun 2017 Tentang Penyelenggaraan Imunisasi. Imunisasi dasar lengkap adalah imunisasi yang diberikan pada usia 0-2 bulan meliputi 1 dosis Hepatitis B pada usia 0-24 jam, 1 dosis BCG dan Polio (OPV) pada usia 1 bulan, 3 dosis DPT-HB-HiB dan OPV/IPV pada usia 2, 3, dan 4 bulan, ditambah 1 dosis imunisasi Campak pada usia 9 bulan. 
Imunisasi lanjutan pada baduta meliputi 1 dosis DPT-HB-Hib dan Campak yang diberikan dalam rentang usia 18-24 bulan. (Permenkes, 2017)

Data yang dianalisis adalah laporan rutin pelayanan imunisasi dasar dan imunisasi lanjutan yang didapat dari Sub Direktorat Imunisasi, Direktorat Surveilans dan Karantina Kesehatan, Direktorat Jenderal Pencegahan dan Penanggulangan Penyakit, Kementerian Kesehatan Republik Indonesia. Persetujuan menggunakan data telah diberikan oleh pihak berwenang, data diperoleh dalam bentuk file excel dan dianalisis menggunakan uji Chi-square dan korelasi bivariat Pearson, menggunakan program komputer. Hubungan antar variabel dianggap bermakna apabila dalam uji statistik didapatkan nilai $\mathrm{p}<0,05$.

\section{HASIL DAN PEMBAHASAN}

Data pelayanan imunisasi yang dilaporkan Dinas Kesehatan Provinsi ke Kementerian Kesehatan adalah program imunisasi rutin, meliputi imunisasi dasar dan imunisasi lanjutan. Imunisasi dasar diberikan pada bayi sebelum usia satu tahun, sedangkan imunisasi lanjutan terdiri atas imunisasi untuk bayi usia di bawah dua tahun (baduta), anak usia sekolah dasar, dan wanita usia subur (WUS). (Permenkes, 2017) Pemberian imunisasi dasar bertujuan membentuk perlindungan terhadap penyakit hepatitis $\mathrm{B}$, poliomyelitis, tuberculosis, difteri, pertussis, tetanus, pneumonia dan meningitis yang disebabkan oleh Hemophilus Influenza tipe b (Hib), dan campak. Imunisasi lanjutan dimaksudkan untuk memperkuat daya tahan tubuh dari penyakit difteri, pertusis, tetanus, hepatitis B, pneumonia dan meningitis yang disebabkan oleh Hemophilus Influenza tipe b (Hib), serta campak.

Profil capaian imunisasi dasar dan imunisasi lanjutan selama pandemi tahun 2020 mengalami penurunan di semua jenis imunisasi dibandingkan capaian tahun 2019. Penurunan cakupan imunisasi IPV paling besar $(-46,1 \%)$ dari profil capaian imunisasi lainnya. Secara keseluruhan terjadi perubahan yang bermakna $(\mathrm{p}<0,0005)$ sebelum dan sesudah pandemi COVID-19. Data selengkapnya dapat dipelajari pada Tabel 1.

Tabel 1. Profil capaian imunisasi dasar/lanjutan sebelum dan selama pandemi COVID-19

\begin{tabular}{|c|c|c|c|c|c|}
\hline \multirow[t]{2}{*}{ Imunisasi } & \multirow[t]{2}{*}{ Usia } & \multicolumn{2}{|c|}{$\begin{array}{c}\text { Capaian imunisasi } \\
(\%)\end{array}$} & \multirow{2}{*}{$\begin{array}{c}\text { Perubahan } \\
\text { capaian } \\
\text { imunisasi }\end{array}$} & \multirow[t]{2}{*}{ Nilai $\mathrm{p}$} \\
\hline & & th 2019 & th 2020 & & \\
\hline \multicolumn{6}{|l|}{ Imunisasi dasar } \\
\hline Hepatitis B & $0-24$ jam & 94,5 & 83,2 & $-11,3$ & \\
\hline OPV 1 & 1 bulan & 95,5 & 82,0 & $-13,5$ & \\
\hline BCG & 1 bulan & 96,0 & 83,1 & $-12,9$ & \\
\hline OPV 2 & 2 bulan & 97,2 & 83,6 & $-13,6$ & \\
\hline DPT-HB-Hib 1 & 2 bulan & 98,2 & 83,5 & $-14,7$ & \\
\hline OPV 3 & 3 bulan & 95,9 & 81,7 & $-14,2$ & \\
\hline DPT-HB-Hib 2 & 3 bulan & 97,1 & 81,7 & $-15,4$ & \\
\hline OPV 4 & 4 bulan & 94,2 & 79,5 & $-14,7$ & \\
\hline IPV & 4 bulan & 77,0 & 30,9 & $-46,1$ & \\
\hline DPT-HB-Hib 3 & 4 bulan & 96,5 & 80,5 & $-16,0$ & \\
\hline Campak & 9 bulan & 95,2 & 79,6 & $-15,6$ & \\
\hline Imunisasi dasar lengkap & & 93,7 & 76,7 & $-17,0$ & $\mathrm{p}<0,0005$ \\
\hline \multicolumn{6}{|l|}{ Imunisasi lanjutan } \\
\hline DPT-HB-Hib & 18 bulan & 75,9 & 62,7 & $-13,2$ & \\
\hline Campak & 18 bulan & 72,7 & 60,0 & $-12,7$ & \\
\hline Imunisasi lanjutan lengkap & & 74,3 & 61,4 & -12.9 & $\mathrm{p}<0,0005$ \\
\hline
\end{tabular}

Keterangan: $\mathrm{BCG}=$ Bacille Calmette Guerin; OPV = oral polio vaccine; IPV = inactivated polio vaccine; DPT-HB-Hib = diphtheria, pertussis, tetanus - hepatitis B - hemophilus influenzae type $b$. 
Pada gambar 1a dapat dilihat bahwa penurunan cakupan imunisasi dasar terjadi di seluruh provinsi Indonesia, yang paling terdampak adalah DI Yogyakarta $(-53,6 \%)$ dan Maluku Utara (41,3\%). Gambar 1b menyajikan penurunan cakupan imunisasi lanjutan terjadi di 33 provinsi, perubahan terbesar dialami provinsi Maluku (-35,2\%) dan DI Yogyakarta $(-32,1 \%)$, dengan perkecualian Nusa Tenggara Timur yang mengalami kenaikan capaian $(7,8 \%)$. Dalam skala nasional, terjadi penurunan capaian imunisasi dasar dari 93,7\% sebelum pandemi di tahun 2019 menjadi 76,7\% selama pandemi tahun 2020 (-17,0\%) dan imunisasi lanjutan dari 74,3\% menjadi $61,4 \%(-12,9 \%)$.

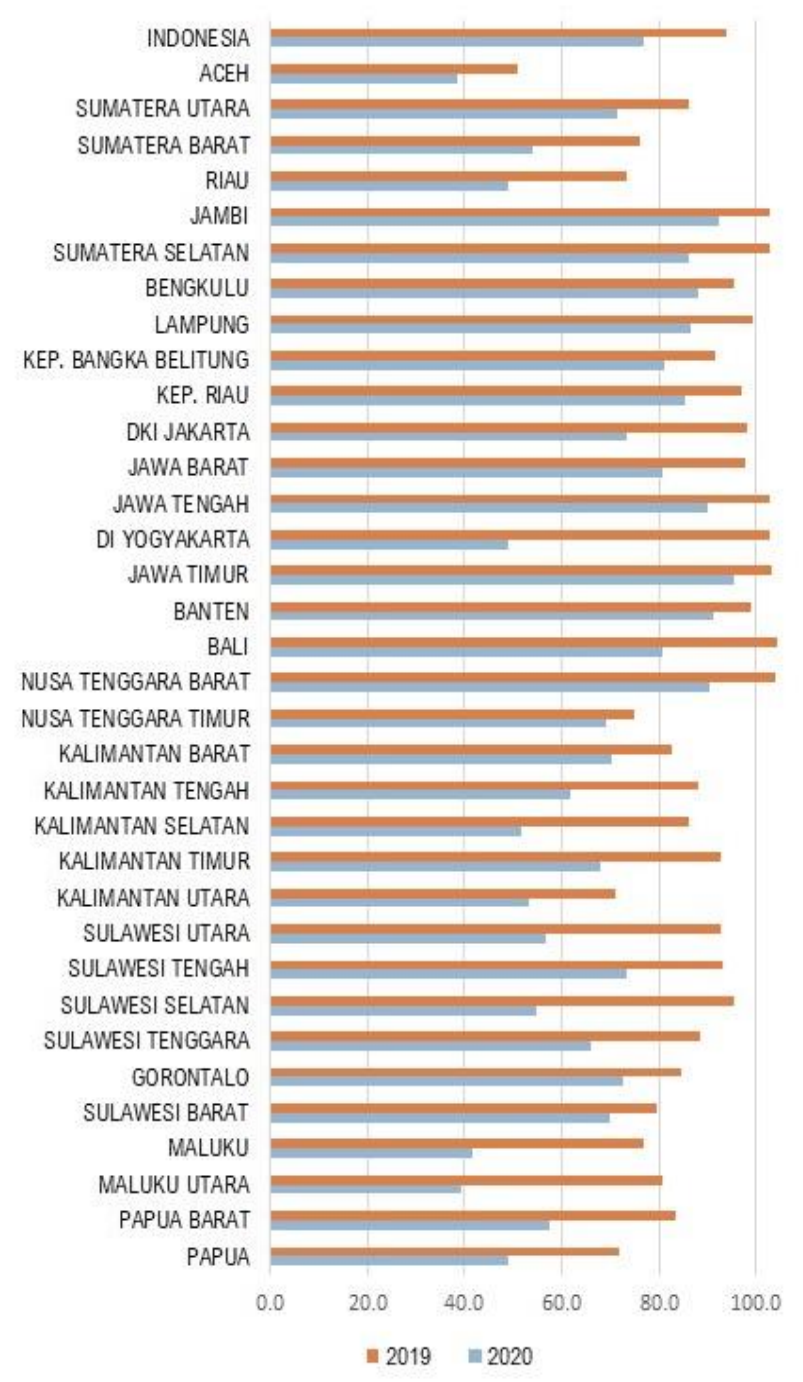

a. Imunisasi dasar

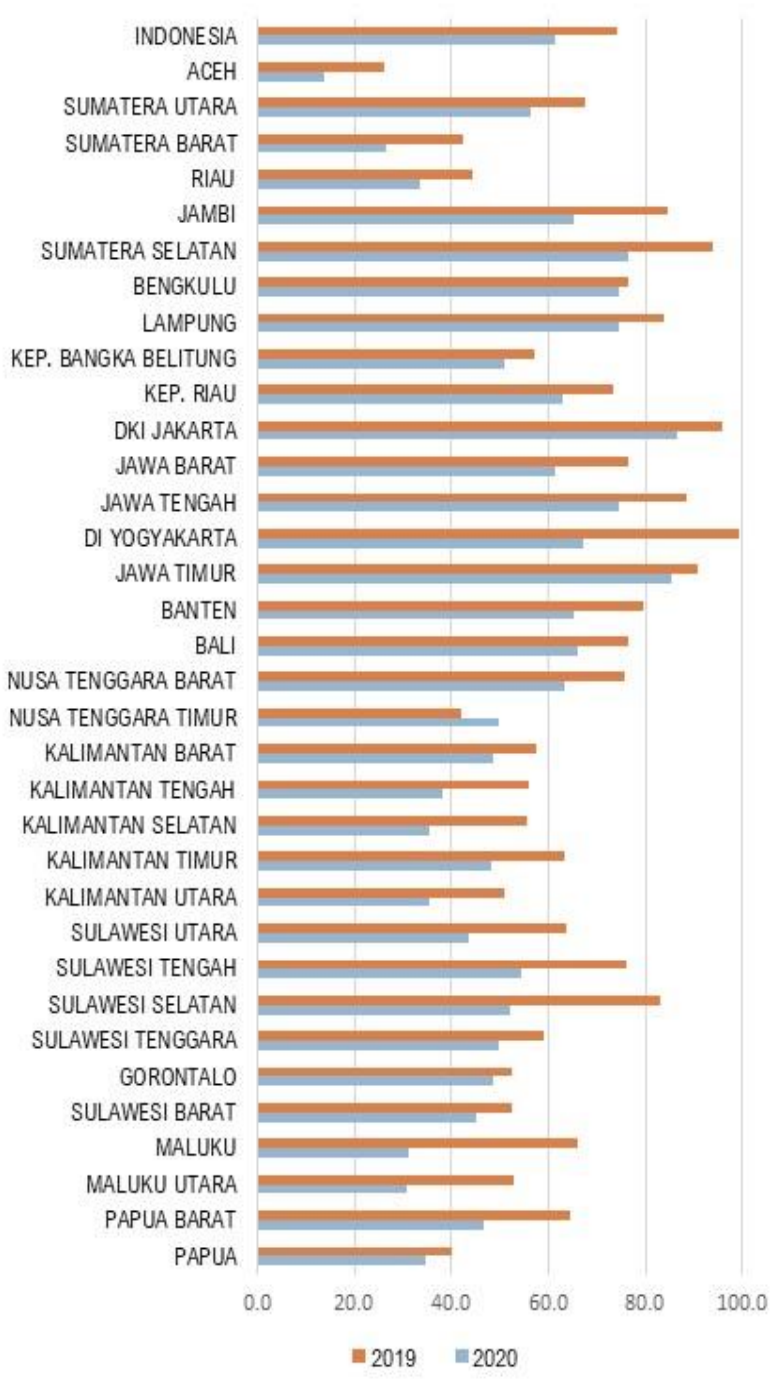

b. Imunisasi lanjutan

Gambar 1. Profil capaian imunisasi dasar/lanjutan dari 34 provinsi di Indonesia sebelum dan selama pandemi COVID-19

Provinsi DKI Jakarta yang memiliki 37.023 kasus per satu juta peduduk menduduki peringkat teratas di zona merah atau zona risiko tinggi COVID-19, disusul Kalimantan Timur, Kalimantan Utara, Bali, DI Yogyakarta dan lima provinsi lain mengalami penurunan capaian imunisasi dasar dan imunisasi lanjutan dibandingkan tujuh provinsi yang temasuk zona oranye dan tujuh belas provinsi dalam kelompok zona kuning. Tidak ada provinsi di Indonesia yang bisa dikategorikan sebagai zona hijau atau daerah tanpa kasus COVID-19. Data capaian imunisasi dasar $(-35,4 \%)$ dan imunisasi lanjutan $(35,2 \%)$ di Maluku yang berzona oranye menunjukkan penurunan lebih tinggi dari rerata perubahan di zona merah. Profil imunisasi dasar dan imunisasi lanjutan 
terendah (masing-masing 38,4\% dan 13,8\%) dimiliki provinsi Aceh yang melaporkan 1.870 kasus terkonfirmasi per satu juta penduduk sehingga zonasi risiko pandeminya tergolong dalam zona kuning. Temuan ini disajikan dalam tabel 2, jika ditinjau berdasarkan zona risiko pandemi, diketahui profil capaian imunisasi dasar memiliki hubungan yang bermakna secara statistik ( $\mathrm{p}<$ $0,05)$, namun berkorelasi lemah berlawanan $(-0,5<\mathrm{r}<-0,3)$ terhadap peningkatan kasus di suatu wilayah. Sedangkan penurunan cakupan imunisasi lanjutan yang terjadi selama pandemi COVID-19 berkorelasi sangat lemah berlawanan $(r>-0,3)$ dan tidak memiliki hubungan yang bermakna secara statistik $(\mathrm{p}>0,05)$ dengan zona risiko pandemi.

Tabel 2. Profil capaian imunisasi dasar/lanjutan berdasar zona risiko pandemi COVID-19

\begin{tabular}{|c|c|c|c|c|c|}
\hline \multirow[t]{2}{*}{ Imunisasi } & \multirow[t]{2}{*}{ Zona risiko } & \multicolumn{2}{|c|}{$\begin{array}{c}\text { Capaian imunisasi } \\
(\%)\end{array}$} & \multirow{2}{*}{$\begin{array}{c}\text { Perubahan } \\
\text { capaian } \\
\text { imunisasi }\end{array}$} & \multirow[t]{2}{*}{ Nilai p } \\
\hline & & th 2019 & th 2020 & & \\
\hline \multirow[t]{4}{*}{ Imunisasi dasar lengkap } & Merah & 91,3 & 63,0 & $-28,3$ & \\
\hline & Oranye & 88,6 & 68,9 & $-19,7$ & \\
\hline & Kuning & 87,1 & 76,4 & $-10,7$ & $\mathrm{p}=0,038$ \\
\hline & Hijau* & - & - & - & $r=-0,358$ \\
\hline \multirow[t]{4}{*}{ Imunisasi lanjutan lengkap } & Merah & 70,2 & 52,7 & $-17,5$ & \\
\hline & Oranye & 65,9 & 51,8 & $-14,0$ & \\
\hline & Kuning & 63,8 & 55,7 & $-8,1$ & $p=0,369$ \\
\hline & Hijau $^{*}$ & - & - & - & $r=-0,159$ \\
\hline
\end{tabular}

Keterangan: Zona merah = risiko tinggi, zona oranye $=$ risiko sedang, zona kuning = risiko rendah, zona hijau = tidak ada kasus COVID-19 (*tidak ada provinsi berstatus zona hijau).

Kegagalan program imunisasi rutin tidak hanya terjadi di Indonesia, hal ini telah diramalkan sejak beberapa pekan awal pandemi COVID-19, dari data-data di negara yang mendapat kasus cukup tinggi. Januari-April 2020 di Prancis, aktivitas dokter umum dilaporkan turun 44\% dan spesialis medis rawat jalan berkurang 71\%. Pada awal April 2020, jumlah kunjungan ke praktik perawatan rawat jalan anak di Amerika Serikat (AS) menyusut sekitar 60\%. (Lazi, et al, 2021) Survei yang dilakukan di 21 negara bagian India (Shet, et al, 2021) terhadap penyedia layanan kesehatan anak melaporkan penangguhan layanan vaksinasi selama pandemi COVID-19 oleh $83,1 \%$ pusat perawatan kesehatan primer, sekunder atau tersier. Pemanfaatan vaksinasi rutin di Lebanon (Mansour, et al, 2021) mengalami penurunan sebesar 31\%, di sektor swasta penyediaan layanan imunisasi berkurang 46,9\% sedangkan dosis vaksin yang diberikan di sektor publik menurun 20\%. Tingkat penurunan tertinggi diamati untuk vaksin oral poliovirus (OPV) dan hepatitis A, diikuti oleh vaksin campak dan konjugasi pneumokokus.

Penyebab rendahnya capaian imunisasi pada masa pandemi telah dipaparkan oleh peneliti dari beberapa negara. Survei terhadap orangtua di Saudi Arabia (Almoosa, et al, 2021) mengungkap fakta meskipun sebagian besar orang tua $(82,8 \%)$ mengetahui bahwa vaksin harus diberikan pada waktunya, tetapi satu dari setiap tiga anak $(33,1 \%)$ melewatkan vaksinasi rutin mereka selama pandemi COVID-19. Kelompok anak-anak yang tidak diimunisasi meluas selama lockdown, meningkatkan kerentanan mereka terhadap penyakit yang dapat dicegah dengan imunisasi. ${ }^{9}$ Studi di Sub-Sahara Afrika (Buonsens, et al, 2020) menyimpulkan ayah yang berpendidikan lebih cenderung untuk mendapatkan imunisasi lengkap. Adanya hubungan yang signifikan diamati antara anak yang tidak melengkapi imnisasi rutin dengan jarak perjalanan dan kesulitan transportasi yang menghalangi orang tua untuk mengunjungi pusat imunisasi selama pandemi $(42,9 \%)$. Alasan lain penurunan pemberian imunisasi adalah ketakutan anak terkena infeksi Covid-19 akibat kunjungan ke rumah sakit $(52,9 \%)$ dan mencurigai bahwa anaknya akan ditangani oleh petugas yang sama dengan tim medis Covid-19. 
Felicia dan Suarca (2020) dari SMF Ilmu Kesehatan Anak RSUD Wangaya Kota Denpasar, Bali, telah melaporkan studi potong lintang terhadap data kunjungan imunisasi poliklinik anak pada periode Januari-Juli 2020 dan 2019 dengan angka cakupan sebesar 13,1\% dan 21,9\% (p<0,001). Terganggunya layanan vaksinasi anak di fasilitas kesehatan setempat dijelaskan dalam penelitian Marhami, dkk (2021), bahwa orangtua kesulitan mendapatkan imunisasi rutin untuk bayinya karena fasilitas kesehatan menghentikan sementara layanan vaksinasi. Sejumlah responden menunda imunisasi wajib untuk anak mereka, dengan alasan kesibukan pekerjaan $(27,4 \%)$ dan kekhawatiran terhadap paparan infeksi COVID-19 jika anak dibawa ke luar rumah $(60,9 \%) .{ }^{12}$ Ada banyak alasan teknis yang menyebabkan penurunan profil capaian imunisasi rutin selama pandemi. Pembatasan mobilisasi warga membuka Posyandu dan penangguhan distribusi vaksin juga menghambat jangkauan cakupan imunisasi. Ketersediaan Alat Pelindung Diri (APD) dan petugas kesehatan untuk vaksinasi makin langka karena alokasi penempatan mereka ke gugus tugas tanggap COVID-19 ikut memperburuk masalah pelayanan imunisasi dasar dan imunisasi lanjutan pada baduta. (Suwantika, 2020)

Pandemi saat ini ditengarai semakin meningkatkan variabilitas antara lokasi, prioritas lokal, dan kesenjangan sosial ekonomi. Dalam keragaman sub-nasional ini, tantangan geografis dan logistik serta prioritas pemerintah daerah merupakan faktor kritis. Program imunisasi rutin harus diaktifkan kembali segera setelah kondisinya stabil, dan dapat menjadi indikasi utama dari sistem kesehatan yang merehabilitasi dalam konteks pasca krisis. Menurut Rawat (2021), untuk mendukung proses rehabilitasi, strategi dan pendekatan komunikasi yang dikembangkan dengan baik diperlukan untuk menginformasikan kepada pemangku kepentingan, dan masyarakat luas tentang potensi dampak pandemi COVID-19 dan strategi mitigasi khusus terhadap kelangsungan dan kinerja dari program imunisasi. Penyedia layanan kesehatan primer memainkan peran kunci dalam memastikan bahwa anak-anak dan masyarakat menerima imunisasi tepat waktu. Peran ini mencakup tugas untuk meyakinkan orang tua yang ragu akan vaksin bahwa vaksin itu aman dan efektif. Sebelum tahun 2020, banyak orang tua belum melihat konsekuensi yang menghancurkan dari penyakit menular. Pandemi dapat mengubah cara pandang orang tua, didukung oleh promosi pentingnya anak sehat dan kunjungan vaksinasi.

\section{KESIMPULAN DAN SARAN}

Penelitian ini menyimpulkan adanya gangguan yang signifikan terhadap profil capaian imunisasi dasar dan imunisasi lanjutan pada baduta di Indonesia selama pandemi COVID-19. Telah terjadi penurunan praktik pelayanan imunisasi dasar sebesar $-17,0 \%(\mathrm{p}<0,0005)$ dan imunisasi lanjutan $-12,9 \%$ ( $p<0,0005$ ) dibandingkan sebelum masa pandemi. Hasil uji statistik menyatakan profil capaian imunisasi dasar memiliki hubungan yang bermakna secara statistik $(\mathrm{p}<0,05)$ terhadap peningkatan kasus di suatu wilayah, namun berkorelasi lemah berlawanan $(-0,5<\mathrm{r}<-0,3)$. Penurunan cakupan imunisasi lanjutan yang terjadi selama pandemi COVID-19 berkorelasi sangat lemah berlawanan $(r>-0,3)$ dan tidak memiliki hubungan yang bermakna secara statistik $(\mathrm{p}>0,05)$ dengan zona risiko pandemi.

Beberapa alasan diduga menjadi penyebab kegagalan program imunisasi di masa pandemi, di antaranya pembatasan layanan rutin untuk anak sehat di fasilitas kesehatan, perubahan ketentuan penyelenggaraan Posyandu, kekurangan petugas dan APD, kesibukan orangtua beradaptasi dengan pekerjaan, dan adanya rasa takut terinfeksi COVID-19 jika bayi dibawa imunisasi. Keputusan orangtua menunda vaksinasi wajib untuk anak mereka, membutuhkan strategi yang lebih kuat untuk mengedukasi pentingnya memberian imunisasi lengkap, sekaligus memastikan layanan vaksinasi dasar dan lanjutan untuk baduta tersedia untuk semua anak di negara ini selama pandemi. Pembenahan protokol dan dukungan pelaksanaan imunisasi di fasilitas layanan 
kesehatan serta penyebaran informasi edukasi pentingnya imunisasi penting diupayakan agar profil capaian imunisasi dasar dan imunisasi lanjutan dapat ditingkatkan.

\section{REFERENSI}

Almoosa, Z., Alhamoud, H.H., Alkhalaf, A.B., Alabdullah, W.A., Alghafli, J.A., Albensaad, M.S., et al. (2021). Impact of coronavirus disease 2019 (COVID-19) pandemic on routine pediatric vaccination in Eastern Region, Saudi Arabia. J Vaccines Vaccin, 11,435.

Buonsenso, D., Cinicola, B., Kallon, M.N., Iodice, F. (2020). Child healthcare and immunizations in Sub-Saharan Africa during the COVID-19 pandemic. Front Pediatr, 8:517. https://doi.org/10.3389/fped.2020.00517.

Felicia, F.V., Suarca, K. (2020). Pelayanan imunisasi dasar pada bayi di bawah usia 12 bulan dan faktor yang memengaruhi di RSUD Wangaya Kota Denpasar selama masa pandemi COVID-19. Sari Pediatri, 22:3,139-145.

Lassi, Z.S., Naseem, R., Salam, R.A., Siddiqui, F., Das, J.K. (2021). The impact of the COVID19 pandemic on immunization campaigns and programs: a systematic review. Int $J$ Environ Res Public Health, 18,988. https://doi.org/10.3390/ijerph 18030988.

Mansour, Z., Arab, J., Said, R., Rady, A., Hamadeh, R., Gerbaka, B., et al. (2021). Impact of COVID-19 pandemic on the utilization of routine immunization services in Lebanon. PLoS ONE,16(2):e0246951. https://doi.org/10.1371/journal. pone.0246951

Marhami, F., Anwar, S., Yufika, A., Bakhtiar, B., Wardani, E., Winardi, W., dkk. (2021). Disruption of childhood vaccination during the COVID-19 pandemic in Indonesia. Narra $J, 1: 1$.

Menteri Kesehatan RI. (2017). Peraturan Menteri Kesehatan Republik Indonesia nomor 12 tahun 2017 tentang Penyelenggaraan Imunisasi. Diunduh dari: https://peraturan.bpk.go.id/Home/ Details/111977/permenkes-no-12-tahun-2017 (diakses tanggal 6 Maret 2021).

Nelson, R. (2020. COVID-19 disrupts vaccine delivery. Lancet Infect Dis, 20,546.

Roberton, T., Carter, E.D., Chou, V.B., Stegmuller, A.R., Jackson, B.D., Tam, Y., et al. (2020). Early estimates of the indirect effects of the COVID-19 pandemic on maternal and child mortality in low-income and middle-income countries: a modelling study. Lancet Glob Health, 8,901-908.

Shet, A., Dhaliwal, B., Banerjee, P., Carr, K., DeLuca, A., Britto, C., et al. (2021). COVID-19related disruptions to routine vaccination services in India: perspectives from pediatricians. medRxiv preprint server. 2021.01.25.21250040; doi: https://doi.org/10.1101/ 2021.01.25.21250040,

Suwantika, A.A., Boersma, C., Postma, M.J. (2020). The potential impact of COVID-19 pandemic on the immunization performance in Indonesia, Expert Review of Vaccines, 19:8,687-690, https://doi.org/10.1080/14760584.2020.1800461.

Rawat, M., Sehrawat, A. (2021). Effect of COVID-19 on routine pediatric vaccination. Asian J Ped Research, pp 14-16. https://doi.org/10.9734/ajpr/2020/v4i430155

UNICEF. Immunization coverage: are we losing ground? (2020). Diunduh dari: https://data. unicef.org/resources/immunization-coverage-are-we-losing-ground/ (diakses pada 6 Maret 2021).

World Health Organization. WHO and UNICEF warn of a decline in vaccinations during COVID-19. (2020). Diunduh dari: https://www.who.int/news/item/15-07-2020-who-andunicef-warn-of-a-decline-in-vaccinations-during-covid-19 (diakses pada 6 Maret 2021). 